\title{
FEM-Based Benchmark Problem for Cogging Torque Minimization of Axial Flux Permanent-Magnet Motors in Artap Framework
}

\author{
Attila Nyitrai ${ }^{1 *}$, Tamás Orosz ${ }^{2}$ \\ ${ }^{1}$ Multidisciplinary Doctoral School of Engineering Sciences, Széchenyi István Univeryity, 1 Egyetem tér, 9026 Győr, Hungary \\ 2 Department of Theory of Electrical Engineering, Faculty of Electrical Engineering, University of West Bohemia, Univerzitní 2732/8, \\ 30100 Pilsen, Czech Republic \\ * Corresponding author, e-mail: nyitrai.attila@sze.hu
}

Received: 27 December 2020, Accepted: 25 February 2021, Published online: 22 April 2021

\begin{abstract}
Optimization of axial flux permanent-magnet motors is a very important topic in the literature and requires high performance optimization algorithms and finite element analysis. This paper gives a summary of the analysis methods of axial flux permanentmagnet motors currently available in the literature. An open-circuit model was built and described using the 2D Linear Motor Modeling Approach. The model was validated by comparing air-gap flux-density waveform and cogging torque results with one of the motors described in the literature as a benchmark problem. The aim of the study was to create a method for the axial-flux motor optimization based on the open-circuit finite element model using the Ärtap software. By applying the described method, it is possible to use local and global optimization algorithms, such as evolutionary and genetic algorithms, directly using the finite element analysis results. The proposed finite element model can be used for benchmarking and selecting the most appropriate evolutionary and genetic algorithms for this kind of optimization problems.
\end{abstract}

Keywords

axial flux motor, cogging torque, 2D electromagnetic FEA, equivalent model, optimization

\section{Introduction}

Axial flux motors have been the focus of many research activities. These generally disk-shaped motors have been used mainly in industrial applications and consumer products where the special requirements could meet more effectively by a radial flux machine [1]. Several comparisons and studies about the general properties of axial flux machines are available in the literature. Nevertheless, with the rise of electro-mobility, axial flux motors came back to researchers' interest since they have some unique features that can be used with advantage in traction applications [2]. Optimization plays an important role in the design, especially because the cost-competitive market of electro-mobility and also the environmental concerns and recycling [3]. The application of optimization algorithms for electric motors in e-mobility applications was presented in several studies [4, 5]. Particularly, cogging torque minimization is well documented $[6,7]$. However, most of the applied methodologies uses evolutionary and genetic algorithms, which cannot guarantee that the found optimum is the global optimum. Moreover, due to the no-free lunch theorem of the mathematical optimization, to select the most appropriate metaheuristic, they have to be tested on a similar type of optimization problems. Therefore, similarity criteria may be be used in motor optimization [8].

A brief overview of previous research work on the 2D finite element modeling possibilities and optimization methods is presented in the following sections. Then a benchmarked axial flux machine is selected from the literature and modeled with a 2D linear motor modeling approach in FEMM. FEMM is integrated into the Artapframework by a file link. The proposed solution can be used under Linux and windows.

The realized FEMM model can be downloaded from [9]. The goal of this integration to consider the manufacturing tolerances from the beginning of an optimization and provide a high-quality, FEM-based, realistic benchmark problem to compare different optimization solvers. 
In the following sections a brief overview of previous research work on the 2D finite element modeling possibilities and optimization methods are presented.

\subsection{D electromagnetic modeling of axial flux motors}

Fast evaluation of the motor model is necessary in many applications such as optimization or digital twins, where simplified numerical, or even analytical models can be used [10]. The performance of FEM solvers on electromagnetic problems was presented in [11]. Three different 2D modeling approaches for dual-rotor axial-flux motors have been presented in [12]:

- 2D-LMMA (Linear Motor Modeling Approach)

- 2D-IRMA (Internal Rotor Modeling Approach)

- 2D-ORMA (Outer Rotor Modeling Approach)

Back-EMF waveforms, harmonic content and electromagnetic torque, and cogging torque were analyzed, and the results were compared with $3 \mathrm{D}$ model results and test motor measurements. In conclusion, the properties of the different approaches were compared. The 3D model required 20 times the number of elements compared to the $2 D$-LMMA. However, the 2D-LMMA needs geometrical transformation and more circumferential slices when the $3 \mathrm{D}$ geometry is irregular therefore needs bigger preprocessing effort. Fig. 1 represents the model of the benchmark motor analysis prepared according to the $2 D-L M M A$.

In [13] the authors presented a multi-slice analytical model for predicting the open-circuit magnetic field

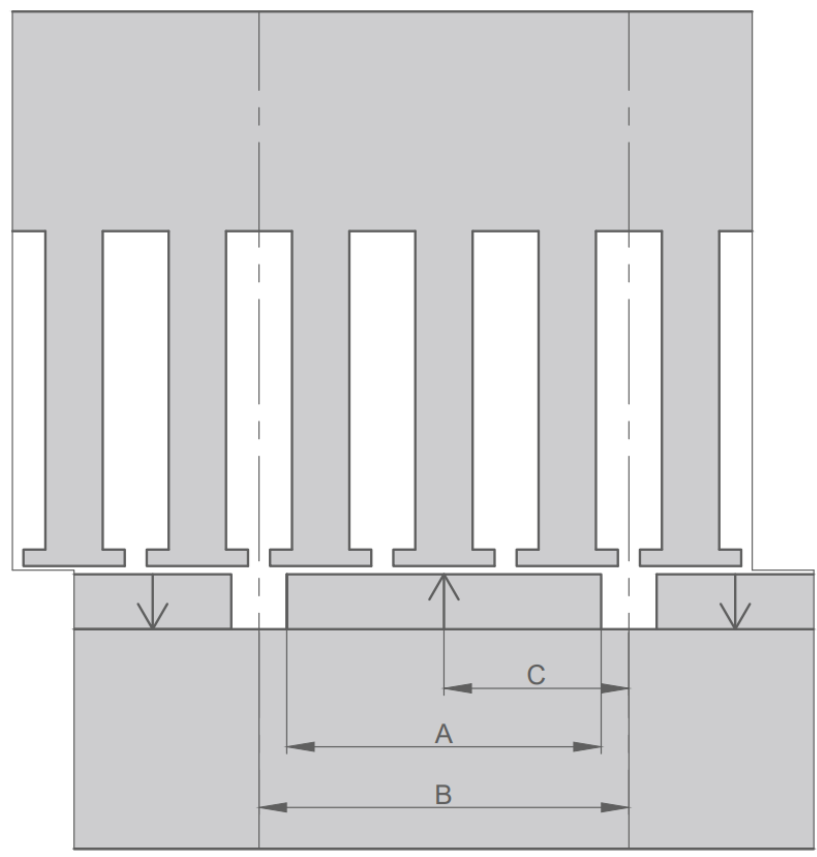

Fig. 1 Geometry and parameters of the finite element model. in slotted semi-closed permanent-magnet axial flux synchronous machines. The technique is based on a 2D exact solution of Maxwell's equations using the separation of variables. Finite element methods validated the results. The approach gives an exact solution on the given topology, however, since the formulation is rather complex, a big effort was necessary to adapt it to other geometries.

The authors described a quasi-3D design program for the rapid evaluation of axial flux motors in [14]. 2D/3D FEA and measurements validated the results. The effect of the number of computational planes on the back-EMF waveform was presented. A reluctance network model for a surface-mounted permanent magnet machine was proposed. In [15] the authors presented a method combining 2D FEM simulations with analytical models based on the Fourierseries theory. The method proposed was to improve the results of the 2D FEA by introducing correction factors. The proposed method was validated by 3D FEA and measurements of a prototype machine.

A dynamic 2D/3D model of an axial flux motor with Soft Magnetic Core (SMC) was presented in [16]. A Magnetic Equivalent Circuit (MEC) was presented in detail. Steadystate and transient calculations were provided and compared to FEA results and measurements. In [17] a 2D Multi-Slice FEA method was presented where the AFPM motor was modeled by three electromagnetically coupled $2 \mathrm{D}$ sections. A hybrid motor was created and analyzed, consisting of permanent magnet rotor with short-circuited cage system. The line-start run-up curve was simulated and measured.

In [18] the authors prepared a nonlinear analytic model of axial flux motors. The model consisted a Magnetic Equivalent Circuit and an analytical model of air-gap permeances. The model was capable of calculating flux-distribution and torque in load conditions.

The model results were compared to 3D FEA results. The benchmark motor parameters were presented in the paper. The machine model was prepared in rectangular coordinate system (2D-LMMA). Based on the developed analytical model a design optimization for torque density and efficiency constraint was presented [8].

According to the mentioned research work, we can conclude that the reduction of the axial flux motor $3 \mathrm{D}$ models to $2 \mathrm{D}$ equivalents results in a reasonable approximation and modeling errors and at the same time reduces the computational cost. These $2 \mathrm{D}$ equivalent models are therefore essential for numerical optimization purposes presented in the next section. 


\subsection{Optimization of axial flux motors}

Optimization problems in electric machines has been always an interesting research field since the advances in optimization methods and algorithms can achieve better results and find close to global optimum solutions [19]. There are therefore many optimization algorithms available, developed to address special problems in computation [20]. However, based on the "no free lunch theorem", the test of the algorithms for performance on a given task is necessary. There are no universal algorithms in search and optimization that would perform equally well on every problem [21]. According to the $1^{\text {st }}$ theorem formulated by Wolpert and Macready [22]:

$$
\sum_{f} P\left(d_{m}^{y} \mid f, m, a_{1}\right)=\sum_{f} P\left(d_{m}^{y} \mid f, m, a_{2}\right),
$$

where $d_{m}^{y}$ is the size $m$ ordered set of cost values of $y$ $f: \boldsymbol{X} \rightarrow \boldsymbol{Y}$ where $x \in \boldsymbol{X}, f$ is the function to optimize and $P\left(d_{m}^{y} \mid f, m, a_{0}\right)$ is the conditional probability of the set $d_{m}^{y}$ running algorithm $a_{0} m$ times on function $f$. The theorem states that if an algorithm applied to a class of problem performs well on that particular class than it is necessary, that the same algorithm performs weaker on the set of all the remaining problems.

In [23] the authors proposed cogging torque reduction techniques for AFPM motors. Different techniques were presented developed mainly for RFPM motors and analyzed by 3D FEM method. Different magnet skewing possibilities were analyzed: conventional, triangular, parallel-sided, trapezoidal and dual skewed. The effect of displaced magnets and variable pole-arcs were analyzed.

A sensitivity study on the efficiency and mass of a $3.6 \mathrm{~kW}$ AFPM generator was presented by the authors in [24]. The machine was modeled by multiple 2D slices of the machine using both analytical and finite element methods. The results were compared with the measurement results of the prototype machine. It was found that the generator efficiency was only moderately sensitive for the mass of the generator.

In [25] the authors described a design approach of axial-flux traction motors. Using a proposed 2D equivalent model, the motor was sized by optimizing it for the efficiency during the given Artemis drive-cycles. The 2D equivalent model was a reluctance network analytical model, suitable for quick evaluation. The performance of the optimized motor was validated by $2 \mathrm{D}$ and 3D FEA. A procedure to calculate pulsating torque components in axial flux machines was provided in [26]. The Torque
Ripple Factor (TRF) for AF machines and its sensitivity to PM pole arc ratio and skewing to angel were presented. A comparison of different motor topologies was carried out. The authors presented a 3D FEA as well.

In [27] the authors provided general sizing equations for the AFIR topology. Design optimization was presented by choosing diameter ratio and air-gap flux-density. Minimization of cogging torque and ripple torque was obtained using FEA.

\section{2D finite-element model of an axial flux motor - LMMA}

In the following section the $2 \mathrm{D}$ finite element model of an $\mathrm{AF}$ motor is presented. The model parameters were the same as in [8] for model validation reason. In [8] the model was validated by 3D FEA and analytical calculations. However, in the current optimization problem, the number of slices was reduced to one in order to reduce computation time.

A magnetostatic analysis [28] was created to determine the cogging torque. The rotor was moved in every analysis step to compute the torque value during the motor operation.

The equations that describe the problem are the followings:

$\nabla \times \boldsymbol{H}=\boldsymbol{J}$,

where $\boldsymbol{H}$ is the magnetic field strength, $\boldsymbol{J}$ is the current density.

$\nabla \cdot \boldsymbol{B}=0$,

where $\boldsymbol{B}$ is the magnetic flux-density. The relationship between $\boldsymbol{B}$ and $\boldsymbol{H}$ for linear materials:

$\boldsymbol{B}=\mu \boldsymbol{H}$.

FEMM uses the magnetic vector potential approach:

$\boldsymbol{B}=\nabla \times \boldsymbol{A}$,

where $\boldsymbol{A}$ is the magnetic vector potential.

Therefore, Eq. (2) can be rewritten in the form:

$\nabla \times\left(\frac{1}{\mu(B)} \nabla \times \boldsymbol{A}\right)=\boldsymbol{J}$,

where $\boldsymbol{B}$ is the magnetic flux-density, $\boldsymbol{A}$ is the magnetic vector potential and $\boldsymbol{J}$ is the current density.

If the material models are isotropic, Eq. (6) can be written in the simplified form:

$-\frac{1}{\mu} \nabla^{2} \boldsymbol{A}=\boldsymbol{J}$. 
The present model was created by following the modeling steps described below:

1. 2D Transformation: the 3D structure of the axial flux motor has been transformed into the equivalent $2 \mathrm{D}$ model by applying geometrical transformation at the mean diameter of the motor. Only one section was used to reduce computation time for the optimization.

2. Find the model symmetries.

3. Define the material properties.

4. Apply the boundary conditions.

5. Prepare the FE mesh.

6. Solve the FE problem.

7. Step the model: change the angular position of the rotor.

The finite element model boundary conditions are presented on Fig. 2. In order to reduce the model size for the optimization, suitable symmetry conditions were applied on the model boundaries. Periodic boundary conditions in FEMM are suitable in this case. The corresponding edges of the model needs to be defined with the same BC.

On the other hand, mesh settings play an important role when air-gap flux-density functions need to be determined. Therefore, appropriately small element size was selected in the air-gap and along the interface between the stator and the rotor. The finite element mesh of the problem can be seen in Fig. 3. A mesh-independence study was carried out in order to check if the problem spatial discretization had negligible effect on the results. The flux-density plot of the model

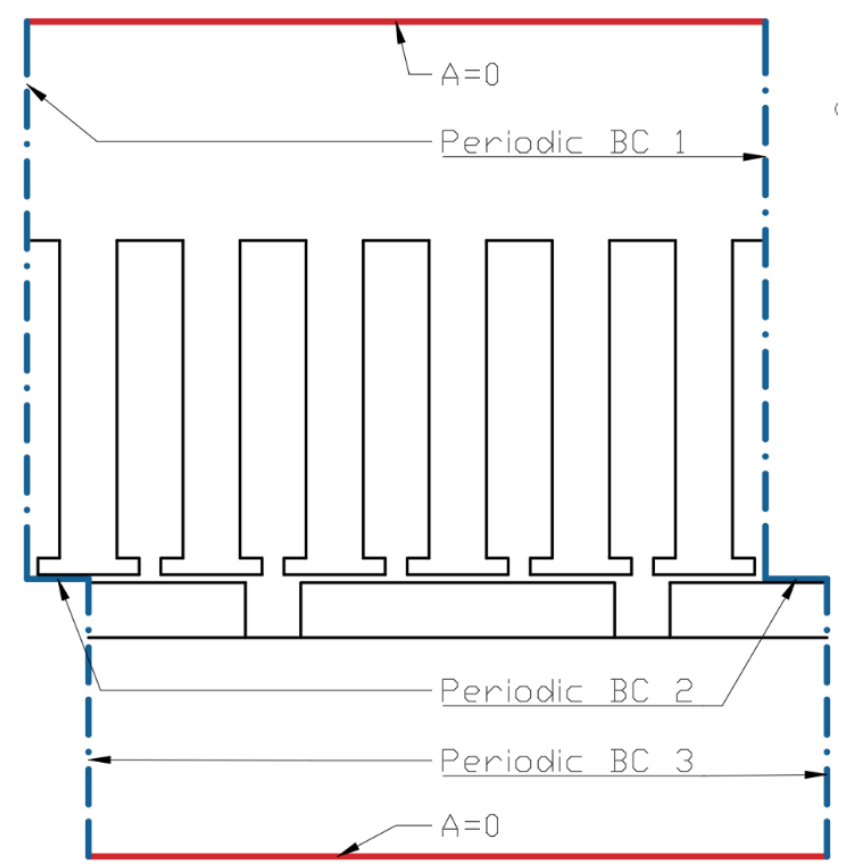

Fig. 2 Boundary conditions of the finite element model.

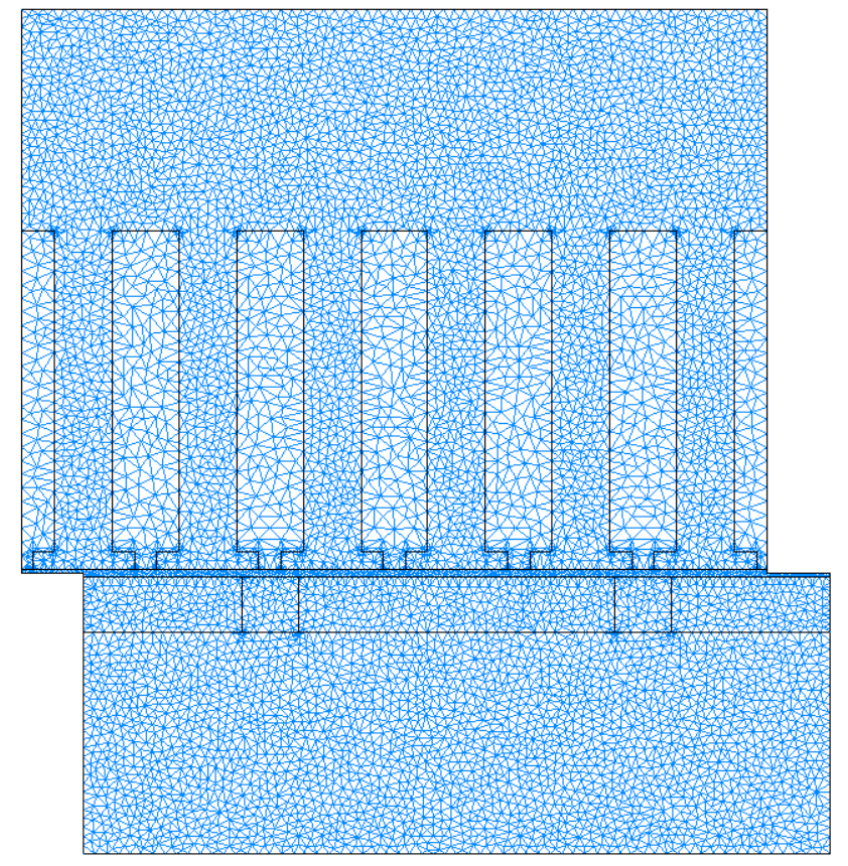

Fig. 3 Finite element mesh.

with the benchmark parameters and the air-gap flux-density functions are presented in Fig. 4 and Fig. 5 respectively.

\section{Optimization}

A basic optimization problem was set-up and solved using the Ārtap software. Ārtap is an MIT licensed robust design optimization framework, which contains a set of numerical solvers and optimization algorithms [29]. Ārtap has an integrated FE solver Agros and has interconnection with several finite element solvers [30]. Compared to other

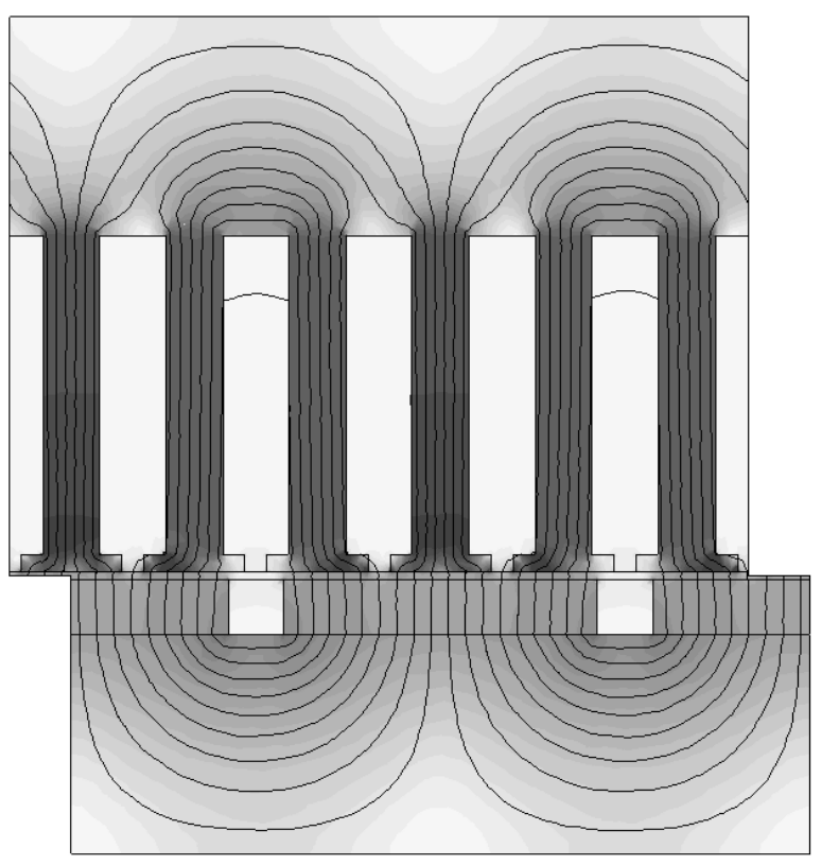

Fig. 4 Flux-density plot of the benchmark AF motor. 


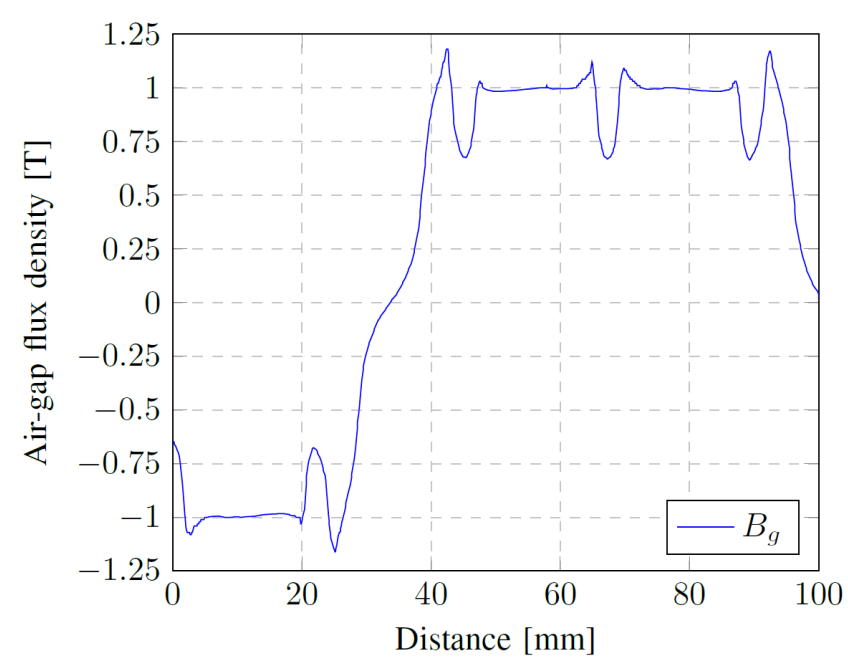

Fig. 5 Air-gap flux-density of the benchmark AF motor.

frameworks, the main advantages of Ârtap are that it is platform-independent, simple-to-use by python scripting and has many in-built optimization algorithms that can be parameterized or modified by the user.

Based on the open-circuit model presented and validated before, the rotor pole pitch ratio $(A / B)$ and pole-shifting $(C)$ were selected as variables to find the optimal values where the cogging torque was minimum.

The cogging torque was calculated by evaluating the cogging-torque vs. displacement curve in the LMMA presented in Fig. 6 The optimization process and the developed framework is presented in Fig. 7.

\subsection{Optimization algorithm and parameters}

The optimization algorithm used was the NSGAII proposed by Deb et al. NSGAII is a non-dominated sorting-based

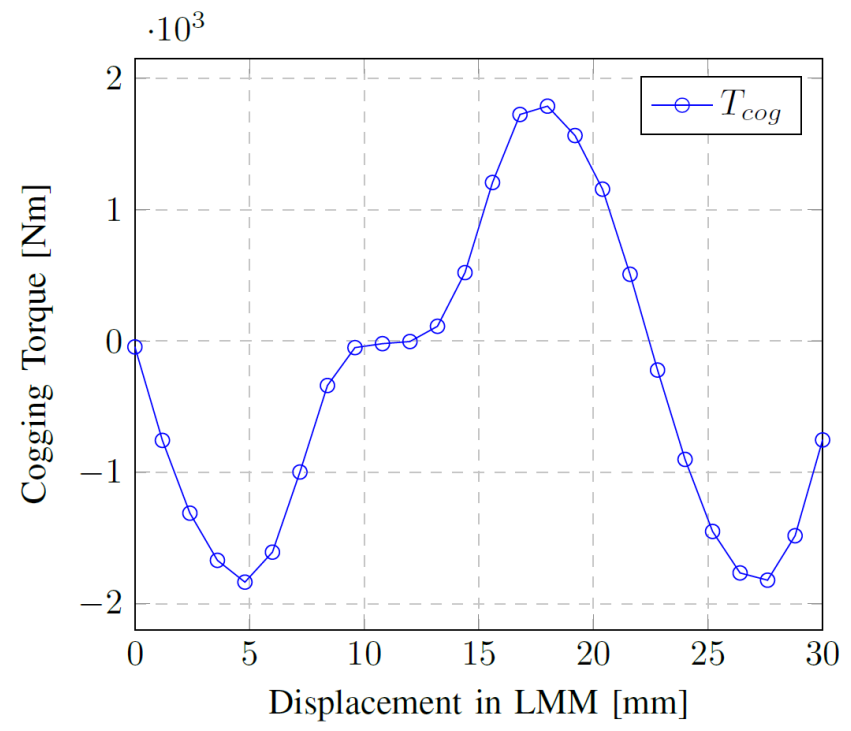

Fig. 6 Cogging-torque of the benchmark AF motor in the LMMA in function of the displacement (rotation equivalent).

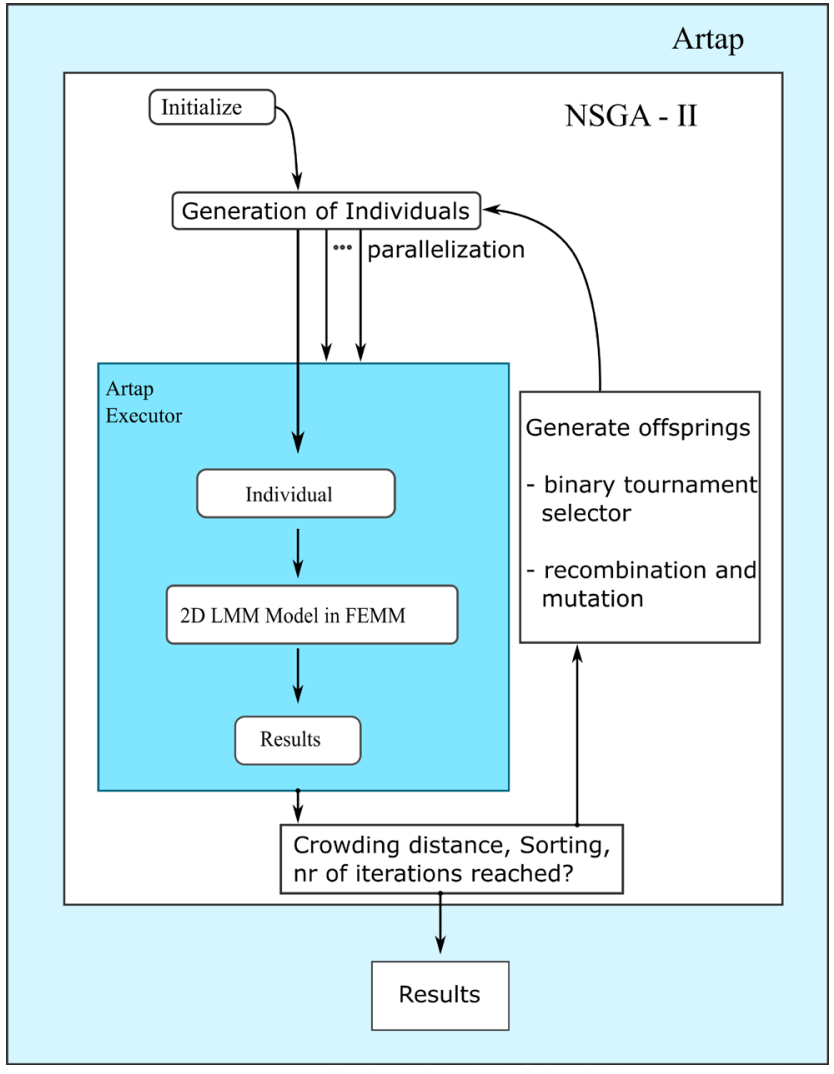

Fig. 7 FEM-based optimization process in Artap using the NSGAII.

multi-objective evolutionary algorithm [31]. The non-dominated sorting genetic algorithm II (NSGAII) has advantages compared to classical non-dominated sorting EAs with $\mathrm{O}\left(M N^{3}\right)$. NSGAII has a faster sorting approach with a computational complexity of $\mathrm{O}\left(M N^{2}\right)[32,33]$.

The parameters of the NSGAII optimization algorithm were as follows in Table 1.

The investigation of the effect of different algorithm parameter sets on the results and to find the most efficient parameter sets will be the scope of a future work.

\subsection{Optimization results}

Using algorithm parameters in Table 1 the geometrical variables of Table 2 were used to run the optimization process. The minimum and maximum values of the variables were set.

\begin{tabular}{lc}
\multicolumn{2}{l}{ Table 1 Optimization algorithm parameters. } \\
\hline Parameter name & Value \\
\hline Max. population size & 15 \\
Max. number of generations & 10 \\
\hline & \\
Table 2 Optimization variables and results.
\end{tabular}

\begin{tabular}{lccc}
\hline Variable name & Minimum & Maximum & Optimum \\
\hline Pole-ratio $(p p)$ & 0.5 & 0.9 & 0.64 \\
Pole-shift $\left(p p \_o f f s e t\right)$ & 0.5 & 0.9 & 0.60 \\
\hline
\end{tabular}




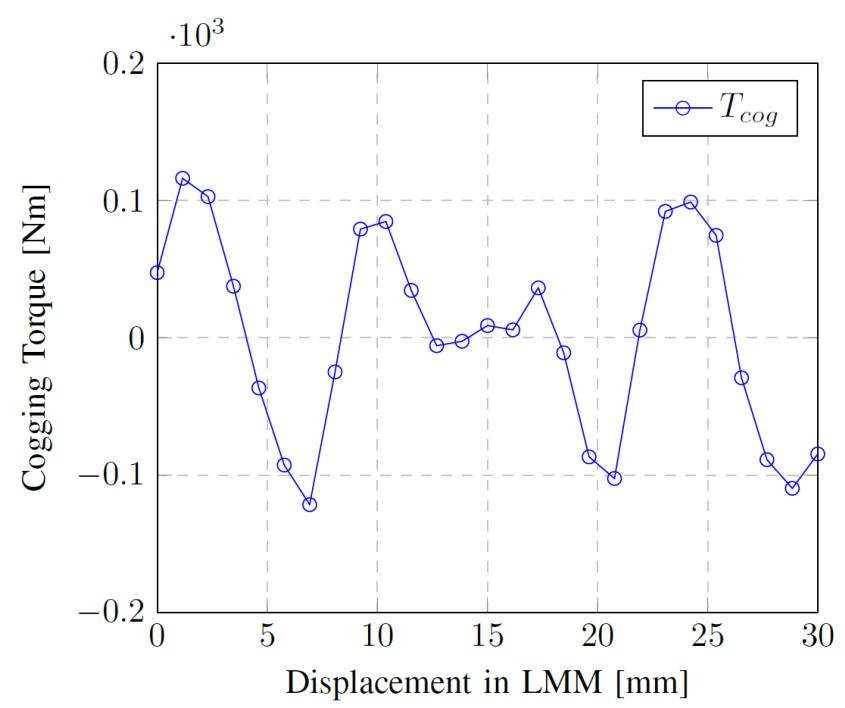

Fig. 8 Cogging-torque of the AF motor with optimized parameters in the LMMA in function of the displacement (rotation equivalent).

The minimized cogging torque function using the optimum parameters is presented in Fig. 8. By applying pole-shifting and different pole-ratios than in the original model, the cogging-torque can be minimized.

\section{Conclusions}

A cogging torque analysis and optimization method for axial flux motors based on the Ārtap framework using the FEMM finite element analysis software was presented. An optimization environment was prepared to use the Ârtap framework's possibilities and an executor for the FEMM's magnetostatic FE solver was implemented to the software. An optimization environment was prepared in order to use the Ārtap framework's possibilities together with FEMM's magnetostatic FE solver. An open-circuit axial flux motor FE model was prepared and validated by studies available in the literature. An optimization problem was solved by applying the NSGAII algorithm:

\section{References}

[1] Patterson, D. J., Colton, J. L., Mularcik, B., Kennedy, B. J., Camilleri, S., Rohoza, R. "A comparison of radial and axial flux structures in electrical machines", In: 2009 IEEE International Electric Machines and Drives Conference, Miami, FL, USA, 2009, pp. 1029-1035.

https://doi.org/10.1109/IEMDC.2009.5075331

[2] Cavagnino, A., Lazzari, M., Profumo, F., Tenconi, A. "A comparison between the axial flux and the radial flux structures for PM synchronous motors", IEEE Transactions on Industry Applications, 38(6), pp. 1517-1524, 2002.

https://doi.org/10.1109/TIA.2002.805572
- the cogging torque was minimized by adjusting the pole-shifting and magnet pitch-pole pitch ratio parameters.

These two parameters have similar effect on the cogging torque as in radial flux permanent magnet motors and the results of this study also proved this assumption. The optimization framework will be used in the future for further investigations of axial flux motors.

The magnetostatic benchmark problem will be used in the future to test and compare other optimization algorithms for electric motor optimization. Given the robust design optimization possibilities of the Ārtap framework, an optimization problem considering the manufacturing tolerances will be addressed in the future.

\section{Nomenclature}

AF Axial Flux

AFIR Axial Flux Internal Rotor

AFPM Axial Flux Permanent Magnet ( Motor)

BC Boundary Condition

EA Evolutionary Algorithm

EMF Electro-Motive Force

FE Finite Element

FEA Finite Element Analysis

FEM Finite Element Modeling

FEMM Finite Element Method Magnetics

IRMA Internal Rotor Modeling Approach

LMMA Linear Motor Modeling Approach

MEC Magnetic Equivalent Circuit

NSGAII Non-dominated Sorting Genetic Algorithm II

PM Permanent Magnet

RFPM Radial Flux Permanent Magnet ( Motor)

SMC Soft Magnetic Core

TRF Torque Ripple Factor

[3] Rassõlkin, A., Kallaste, A., Orlova, S., Gevorkov, L., Vaimann, T., Belahcen, A. "Re-Use and Recycling of Different Electrical Machines", Latvian Journal of Physics and Technical Sciences, 55(4), pp. 13-23, 2018. https://doi.org/10.2478/lpts-2018-0025

[4] Msaddek, H., Mansouri, A., Brisset, S., Trabelsi, H. "Design and optimization of PMSM with outer rotor for electric vehicle", In: 2015 IEEE 12th International Multi-Conference on Systems, Signals \& Devices (SSD15), Mahdia, Tunisia, 2015, pp. 1-6. https://doi.org/10.1109/SSD.2015.7348154 
[5] Fodorean, D., Idoumghar, L., Brévilliers, M., Minciunescu, P., Irimia, C. "Hybrid Differential Evolution Algorithm Employed for the Optimum Design of a High-Speed PMSM Used for EV Propulsion", IEEE Transactions on Industrial Electronics, 64(12), pp. 9824-9833, 2017. https://doi.org/10.1109/TIE.2017.2701788

[6] Zhu, Z. Q., Howe, D. "Influence of design parameters on cogging torque in permanent magnet machines", IEEE Transactions on Energy Conversion, 15(4), pp. 407-412, 2000.

https://doi.org/10.1109/60.900501

[7] Wanjiku, J., Khan, M. A., Barendse, P. S., Pillay, P. "Influence of Slot Openings and Tooth Profile on Cogging Torque in AxialFlux PM Machines", IEEE Transactions on Industrial Electronics, 62(12), pp. 7578-7589, 2015.

https://doi.org/10.1109/TIE.2015.2458959

[8] Rubanenko, O. O., Komar, V. O., Petrushenko, O. Y., Smolar, A., Smailova, S., Imanbekova, U. "Determination of similarity criteria in optimization tasks by means of neuro-fuzzy modelling", Prezgląd Elektrotechniczny, 3, pp. 93-96, 2017.

https://doi.org/10.15199/48.2017.03.22

[9] Karban. P. "artap-framework/artap", [online] Available at: https:// github.com/artap-framework/artap [Accessed: 26 December 2020]

[10] Rassõlkin, A., Rjabtšikov, V., Vaimann, T., Kallaste, A., Kuts, V., Partyshev, A. "Digital Twin of an Electrical Motor Based on Empirical Performance Model", In: 2020 XI International Conference on Electrical Power Drive Systems (ICEPDS), St. Petersburg, Russia, 2020, pp. 1-4. https://doi.org/10.1109/ICEPDS47235.2020.9249366

[11] Kiss, G. M., Kaska, J., de Oliveira, R. A. H., Rubanenko, O., Tóth, B. "Performance Analysis of FEM Solvers on Practical Electromagnetic Problems", [cs.CE], arXiv:2009.04399, Cornell University, Ithaca, NY, USA, 2020. [online] Available at: https:// arxiv.org/abs/2009.04399 [Accessed: 26 December 2020]

[12] Gulec, M., Aydin, M. "Implementation of different 2D finite element modelling approaches in axial flux permanent magnet disc machines", IET Electric Power Applications, 12(2), pp. 195-202, 2018.

https://doi.org/10.1049/iet-epa.2017.0434

[13] Tiegna, H., Bellara, A., Amara, Y., Barakat, G. "Analytical Modeling of the Open-Circuit Magnetic Field in Axial Flux Permanent-Magnet Machines With Semi-Closed Slots", IEEE Transactions on Magnetics, 48(3), pp. 1212-1226, 2012. https://doi.org/10.1109/TMAG.2011.2171979

[14] Parviainen, A., Niemela, M., Pyrhonen, J. "Modeling of axial flux permanent-magnet machines", IEEE Transactions on Industry Applications, 40(5), pp. 1333-1340, 2004. https://doi.org/10.1109/TIA.2004.834086

[15] Egea, A., Almandoz, G., Poza, J., Ugalde, G., Escalada, A. J. "Axial-Flux-Machine Modeling With the Combination of FEM2-D and Analytical Tools", IEEE Transactions on Industry Applications, 48(4), pp. 1318-1326, 2012. https://doi.org/10.1109/TIA.2012.2199450
[16] Maloberti, O., Figueredo, R., Marchand, C., Choua, Y., Condamin, D., Kobylanski, L., Bommé, E. "3D-2D Dynamic Magnetic Modeling of an Axial Flux PM Motor with Soft Magnetic Composites for Hybrid Electric Vehicles", IEEE Transactions on Magnetics, 50(6), Article Number: 8201511, 2014. https://doi.org/10.1109/TMAG.2014.2300152

[17] Hill-Cottingham, R. J., Coles, P. C., Rodger, D., Lai, H. C. "Finite element modelling of an axial flux PM machine", In: Second International Conference on Power Electronics, Machines and Drives (PEMD 2004), Edinburgh, UK, 2004, pp. 552-555. https://doi.org/10.1049/cp:20040347

[18] Kano, Y., Kosaka, T., Matsui, N. "A Simple Nonlinear Magnetic Analysis for Axial-Flux Permanent-Magnet Machines", IEEE Transactions on Industrial Electronics, 57(6), pp. 2124-2133, 2010. https://doi.org/10.1109/TIE.2009.2034685

[19] Orosz, T. "Evolution and Modern Approaches of the Power Transformer Cost Optimization Methods", Periodica Polytechnica Electrical Engineering and Computer Science, 63(1), pp. 37-50, 2019.

https://doi.org/10.3311/PPee.13000

[20] Orosz, T., Rassõlkin, A., Kallaste, A., Arsénio, P., Pánek, D., Kaska, J., Karban, P. "Robust Design Optimization and Emerging Technologies for Electrical Machines: Challenges and Open Problems", Applied Sciences, 10(19), Article Number: 6653, 2020. https://doi.org/10.3390/APP10196653

[21] Orosz, T., Borbély, B., Tamus, Z. Á. "Performance Comparison of Multi Design Method and Meta-Heuristic Methods for Optimal Preliminary Design of Core-Form Power Transformers", Periodica Polytechnica Electrical Engineering and Computer Science, 61(1), pp. 69-76, 2017. https://doi.org/10.3311/PPee.10207

[22] Wolpert, D. H., Macready, W. G. "No free lunch theorems for optimization", IEEE Transactions on Evolutionary Computation, 1(1), pp. 67-82, 1997.

https://doi.org/10.1109/4235.585893

[23] Aydin, M., Zhu, Z. Q., Lipo, T. A., Howe, D. "Minimization of Cogging Torque in Axial-Flux Permanent-Magnet Machines: Design Concepts", IEEE Transactions on Magnetics, 43(9), pp. 3614-3622, 2007. https://doi.org/10.1109/TMAG.2007.902818

[24] Vansompel, H., Sergeant, P., Dupré, L. "Optimized Design Considering the Mass Influence of an Axial Flux Permanent-Magnet Synchronous Generator With Concentrated Pole Windings", IEEE Transactions on Magnetics, 46(12), pp. 4101-4107, 2010. https://doi.org/10.1109/TMAG.2010.2070075

[25] Krebs, G., de Cecco, E., Marchand, C. "Design approach of an axial flux motor for electrical powertrain vehicle", In: 2012 XXth International Conference on Electrical Machines, Marseille, France, 2012, pp. 2812-2817. https://doi.org/10.1109/ICElMach.2012.6350285

[26] Aydin, M., Huang, S., Lipo, T. A. "Torque quality and comparison of internal and external rotor axial flux surface-magnet disc machines", IEEE Transactions on Industrial Electronics, 53(3), pp. 822-830, 2006.

https://doi.org/10.1109/TIE.2006.874268 
[27] Aydin, M., Huang, S., Lipo, T. A. "Optimum design and 3D finite element analysis of nonslotted and slotted internal rotor type axial flux PM disc machines", In: 2001 Power Engineering Society Summer Meeting. Conference Proceedings (Cat. No.01CH37262), Vancouver, BC, Canada, 2001, pp. 1409-1416. https://doi.org/10.1109/PESS.2001.970283

[28] Plonus, M. "Applied electromagnetics", McGraw-Hill, New York, NY, USA, 1978.

[29] Karban, P., Pánek, D., Orosz, T., Petrášová, I., Doležel, I. "FEM based robust design optimization with Agros and Ārtap", Computers \& Mathematics with Applications, 81, pp. 618-633, 2021.

https://doi.org/10.1016/j.camwa.2020.02.010

[30] Karban, P., Pánek, D., Orosz, T., Doležel, I. "Semi-analytical Solution for a Multi-objective TEAM Benchmark Problem", Periodica Polytechnica Electrical Engineering and Computer Science, 2020.

https://doi.org/10.3311/PPee.16093
[31] Deb, K., Pratap, A., Agarwal, S., Meyarivan, T. "A fast and elitist multiobjective genetic algorithm: NSGA-II", IEEE Transactions on Evolutionary Computation, 6(2), pp. 182-197, 2002. https://doi.org/10.1109/4235.996017

[32] Zhu, Z. Q., Ruangsinchaiwanich, S., Schofield, N., Howe, D. "Reduction of cogging torque in interior-magnet brushless machines", In: 2003 IEEE International Magnetics Conference (INTERMAG), Boston, MA, USA, 2003, pp. ER-04. https://doi.org/10.1109/INTMAG.2003.1230613

[33] Jin, L., Zhao, S., Du, W., Yang, X., Wang, W., Yang, Y. "Research on multi-objective optimization of switched flux motor based on improved NSGA-II algorithm", Proceedings of the Institution of Mechanical Engineers, Part E: Journal of Process Mechanical Engineering, 233(6), pp. 1268-1279, 2019. https://doi.org/10.1177/0954408919864185 